\title{
Impact of small bowel capsule endoscopy in iron deficiency anemia: influence of patient's age on diagnostic yield
}

\author{
Sofia XAVIER ${ }^{1,2,3}$, Joana MAGALHÃES ${ }^{1,2,3}$, Bruno ROSA ${ }^{1,2,3}$, Maria João MOREIRA ${ }^{1,2,3}$ and José COTTER $^{1,2,3}$
}

Received 11/2/2018 Accepted 14/8/2018

\begin{abstract}
Background - Iron deficiency anemia remains one of the main indications to perform small bowel capsule endoscopy. Literature suggests that diagnostic yield is influenced by patient's age but with conflicting results regarding age cutoff. Objective - We aimed to clarify the differences in diagnostic yield and incidence of specific findings according to age. Methods - Retrospective single-center study including 118 patients performing small bowel capsule endoscopy in the study of iron deficiency anemia. Videos were reviewed and small bowel findings that may account for anemia were reported. Incomplete examinations were excluded. Findings were compared between patients $\leq 60$ and $>60$ years. Results - Patients had a mean age of 58 years old $(\mathrm{SD} \pm 17.9)$ with $69.5 \%$ females $(\mathrm{n}=82)$. The overall diagnostic yield was $49 \%(58 / 118)$, being higher among patients $>60$ years $(36 / 60$, diagnostic yield $60 \%)$ than those $\leq 60$ years $(20 / 58$, diagnostic yield $34 \%),(P<0.01)$. Angioectasias were more frequent in patients $>60$ years ( $45 \%$ vs $9 \%, P<0.01$ ). Patients $\leq 60$ years presented more frequently significant inflammation (Lewis score $>135$ in $10.3 \%$ vs $1.7 \%, P<0.05$ ) and other non-vascular lesions $(24 \%$ vs $10 \%, P=0.04)$. Conclusion - In our cohort small bowel capsule endoscopy diagnosed clinically relevant findings in the setting of iron deficiency anemia in almost half the patients. Diagnostic yield was higher in patients older than 60 years $(60 \%)$, with vascular lesions being more frequent in this age group. Despite the lower diagnostic yield in patients $\leq 60$ years, significant pathology was also found in this age group, mainly of inflammatory type.
\end{abstract}

HEADINGS - Anemia. Capsule endoscopy. Small intestine.

\section{INTRODUCTION}

Iron deficiency anemia (IDA), the most frequent cause of anemia $^{(1)}$, has a prevalence of $2 \%-7 \%$ in the general population and is particularly frequent in the elderly, with a prevalence of $10-12^{(2)}$. Since chronic occult gastrointestinal bleeding is the main cause for IDA, upper and lower gastrointestinal endoscopies are the first line diagnostic procedures ${ }^{(3)}$. However, about $30 \%$ of patients will have normal bidirectional endoscopy ${ }^{(4)}$, making small bowel endoscopy the next step in the diagnosis.

Capsule endoscopy has become an important aid in clinical practice, providing the diagnosis in many situations that were previously hard to identify. Occult gastrointestinal bleeding (OGIB) remains one of the main indications to perform small bowel capsule endoscopy $(\mathrm{SBCE})^{(5)}$. In this setting, when compared with other small-bowel imaging techniques, SBCE has significantly higher diagnostic yield (DY) than small bowel follow-through, push enteroscopy, CT enteroclysis, CT angiography and MRI, and is comparable to double balloon enteroscopy ${ }^{(6-8)}$. In face of such evidence, current guidelines recommend capsule endoscopy as the first-line investigation of $\mathrm{OGIB}^{(9)}$.

In the setting of IDA, SBCE has a pooled diagnostic yield of $66.6 \%{ }^{(10)}$ influencing subsequent clinical management in $72 \%-75 \%$ of patients with positive $\mathrm{SBCE}^{(11)}$. The most frequent findings are angioectasias but other vascular abnormalities, inflammatory lesions or small bowel tumors can also arise ${ }^{(10)}$.

Current literature suggests that diagnostic yield is influenced by patients' age but with conflicting results regarding the age cutoff ${ }^{(11-14)}$. Also, current evidence suggests that diagnostic findings on SBCE performed in the setting of IDA are influenced by patients' age ${ }^{(11-13)}$. We aimed to assess the diagnostic yield of SBCE in patients with IDA after negative upper endoscopy and colonoscopy, and to clarify the differences in DY and incidence of specific findings according to patients' age.

\section{METHODS}

Retrospective study in a University affiliated Hospital Gastroenterology Department, highly experienced in SBCE. All videos of consecutive SBCE performed in the study of IDA between September 2012 and August 2015 were reviewed, and small-bowel findings that could account for IDA were considered relevant. Those findings included visible hemorrhage or hematic residues, angioectasias, erosions, ulcers, varices, polyp/tumor and significant villous atrophy in proximal small bowel. Patients with inflammatory lesions had their Lewis Score (LS) calculated and were categorized according to the defined and validated cut-offs in three groups non-significant inflammation if $\mathrm{LS}<135$, mild inflammation if LS $135-<790$ and moderate to severe inflammation if $\mathrm{LS} \geq 790^{(15)}$.

Declared conflict of interest of all authors: none

Disclosure of funding: nothing to declare

${ }^{1}$ Hospital Senhora da Oliveira, Departamento de Gastroenterologia, Guimarães, Portugal. ${ }^{2}$ Universidade do Minho, Escola de Medicina, Instituto de Investigação em Ciências da Vida e da Saúde (ICVS), Braga, Portugal. ${ }^{3}$ ICVS/3B's, PT Laboratório Associado do Governo, Guimarães, Braga, Portugal.

Corresponding author: Sofia Xavier. Orcid: 0000-0001-6214-0584.E-mail: smaxavier@gmail.com 
Anemia was defined as hemoglobin below $12 \mathrm{~g} / \mathrm{dL}$ for women and $13 \mathrm{~g} / \mathrm{dL}$ for men and iron deficiency was defined as ferritin $<15 \mathrm{ug} / \mathrm{L}$ for patients with negative inflammatory markers, and ferritin $<50 \mathrm{ug} / \mathrm{L}$ for those with elevated inflammatory markers ${ }^{(3)}$.

All patients had undergone upper and lower gastrointestinal endoscopy before SBCE. SBCE was performed with PillCam ${ }^{\circledR}$ SB2 or SB3 (Medtronic, Minneapolis, MN, USA) using the standard protocol for our unit - clear liquid diet the day before the procedure and a $12 \mathrm{~h}$ night-fast; 30 minutes before capsule ingestion patients were given $100 \mathrm{mg}$ of Simethicone (Aero-OM ${ }^{\circledR}$, OM Pharma) and $1 \mathrm{~h}$ after ingestion they returned to our unit for real time visualization; at this point, if the capsule remained in the stomach, the patient was given Domperidone (Motilium ${ }^{\circledR}$, Janssen). If after prokinetic administration the capsule remained in the stomach, it was passed into the duodenum by upper gastrointestinal endoscopy ${ }^{(16,17)}$.

The complete video obtained in each SBCE was reviewed by two gastroenterologists with vast experience in capsule endoscopy using Rapid ${ }^{\circledR}$ Software, at 8-12 frames per second rate, using when needed FICE technology ${ }^{(18,19)}$.

We collected data on age, gender, capsule type (PillCam ${ }^{\circledR}$ SB2 or SB3), quality of bowel preparation, gastric and small bowel transit time and presence of relevant findings in segments other than small bowel. Incomplete SBCE and repeat examinations for the same patient were excluded. SBCE findings were compared between patients $\leq 60$ and $>60$ years.

Statistical analysis was performed using SPSS v.21.0 and a two-tailed $P$ value $<0.05$ was defined as indicating statistical significance. Categorical variables were presented as frequencies and percentages, and compared with the use of Fisher's exact test or chi-square test, as appropriate. Continuous variables were presented as means and standard deviations and compared with the use of Student's $t$-test.

This study was performed in compliance with ethical standards and all patients signed an informed consent form and consensual contraindications for SBCE procedure were respected as have been described elsewhere ${ }^{(20)}$.

\section{RESULTS}

From September 2012 to August 2015 a total of 357 SBCE were performed, 127 in the study of obscure OGIB. Out of these 127 patients, only 118 were considered for the purpose of this study - five patients had positive stool blood test without anemia and other four capsules were incomplete.

Patients had a mean age of $58 \pm 17.9$ years old (minimum 20, maximum 86 years old) with $69.5 \%$ females $(n=82)$. At the time of SBCE mean hemoglobin was $9.9 \pm 1.4 \mathrm{~g} / \mathrm{dL}$. SBCE was performed with PillCam ${ }^{\circledR}$ SB3 in 64 (54.2\%) patients. Preparation quality was considered good in the vast majority of patients $(66.9 \%)$. Information regarding patients' usual medications and comorbidities are depicted in TABLE 1.

The overall DY was 49.0\% (58/118). No differences were found for DY between PillCam ${ }^{\circledR}$ SB2 and SB3 (50\% vs $45.3 \%, P>0.05$ ) nor between patients with good small bowel preparation when compared with moderate or bad preparations $(41.8 \%$ vs $58 \%, P>0.05)$.

The most frequently reported findings were angioectasias in $27.1 \%$ of SBCE. The frequencies of endoscopic findings are depicted in FIGURE 1.

First, second and third tercile findings were reported in 51\%, $25 \%$ and $30 \%$ of SBCE, respectively, and mean small-bowel transit
TABLE 1. Patients usual medication and comorbidities.

\begin{tabular}{lc}
\hline Usual medication & Percentage (\%) \\
\hline Acetylsalicylic acid & 23.7 \\
Clopidogrel & 0.8 \\
Warfarin & 12.7 \\
Low wheight molecular heparine & 0.0 \\
Comorbidities & \\
Chronic renal failure & 15.3 \\
Hypertension & 64.4 \\
Dyslipidemia & 56.8 \\
Diabetes & 23.7 \\
Chronic liver disease & 5.1 \\
\hline
\end{tabular}

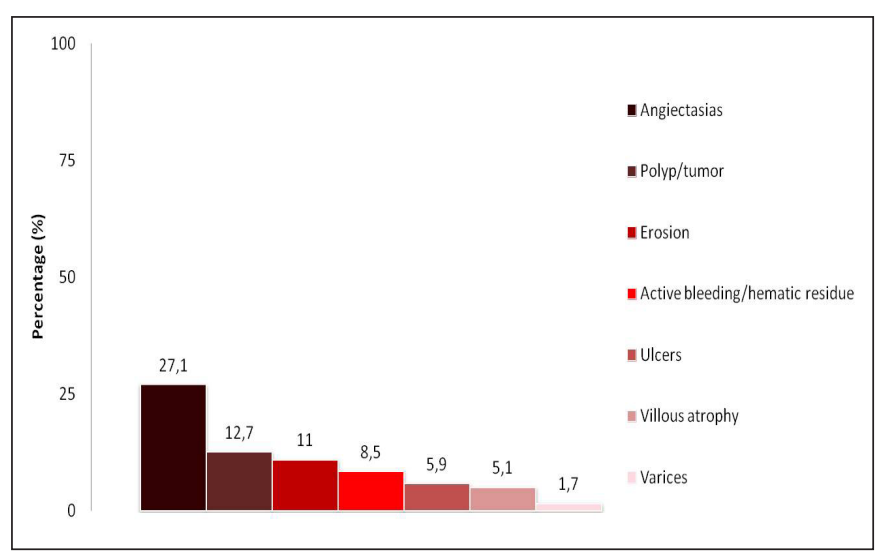

FIGURE 1. Frequency of relevant findings.

time was $274 \pm 105$ minutes. No differences were found between SB2 and SB3 for first ( $42.6 \%$ vs $57.8 \%, P>0.05)$, second ( $25.9 \%$ vs $23.4 \%, P>0.05)$ and third tercile findings $(33.3 \%$ vs $26.6 \%, P>0.05)$ or relevant findings detection ( $50 \%$ vs $45.3 \%, P>0.05)$. SB3 had a significantly higher detection of villous atrophy ( $0 \%$ vs $9.3 \%$, $P=0.03$ ) but both capsules had comparable performances regarding other findings detection.

For patients with small-bowel inflammatory lesions, a LS $>135$ was reported in $5.9 \%$ of $\mathrm{SBCE}(n=6)$.

Relevant findings in segments other than the small bowel were reported in $20.3 \%$ of examinations, mostly in the stomach $(17.8 \%)$ being erosions the most frequently reported finding in these segments $(10.2 \%)$. Half of patients with extra-small bowel findings also had relevant small bowel findings.

DY was significantly higher for males $(63.9 \%$ vs $40.2 \%, P<0.02)$. Also, patients with diagnostic SBCE were significantly older (62.4 vs 54.9 years, $P=0.02$ ) and had longer small bowel transit time (303.6 min vs $247.1 \mathrm{~min}, P<0.01$ ). Even for PillCam ${ }^{\circledR}$ SB3, longer small bowel transit time is significantly associated with significant finding detection on SBCE (254 vs $312 \mathrm{~min}, P=0.026$ ). DY was not influenced by antiplatelet/anticoagulant drugs or patients' co-morbidities (hypertension, dyslipidemia, diabetes mellitus, and chronic renal or hepatic disease).

The mean age of patients with angioectasias was $67 \pm 12.5$ years, while the mean age of patients with non-diagnostic SBCE was $55 \pm 18.4$ years. Patients with inflammatory lesions had a mean age of $45 \pm 15.7$ years (TABLE 2). 
TABLE 2. Mean age according to findings.

\begin{tabular}{lc}
\hline Finding & Patients mean age $\pm \mathrm{SD}$ (years) \\
\hline Angioectasia & $67 \pm 12.5$ \\
Polyp/tumor & $60.9 \pm 18.0$ \\
Erosion & $56.1 \pm 20.6$ \\
Active bleeding/hematic residue & $60.6 \pm 19.8$ \\
Ulcers & $44.9 \pm 16.0$ \\
Villous atrophy & $66.3 \pm 18.0$ \\
Varices & $82.0 \pm 5.7$ \\
No findings & $55 \pm 18.4$ \\
Lewis score $>135$ & $45 \pm 15.7$ \\
\hline
\end{tabular}

Statistically significant differences between DY were found between patients $\leq 60$ years $(20 / 58$, DY $34 \%)$ and those $>60$ years (36/60, DY 60\%), $(P<0.01)$. Angioectasias were more frequently found in patients $>60$ years $(45 \%$ vs $9 \%, P<0.01)$. Also, dyslipidemia and hypertension were significantly more frequent in patients with angiectasia $(51.2 \%$ vs $71.9 \%, P=0.04$ and $58.1 \%$ vs $81.3 \%, P=0.02$, respectively). Patients $\leq 60$ years presented more frequently significant inflammation (Lewis score $>135$ in $10.3 \%$ vs $1.7 \%, P<0.05$ ) and non-vascular lesions (erosions, ulcers, villous atrophy and polyp/tumor) ( $24 \%$ vs $10 \%, P=0.04)$ (FIGURE 2$)$. No differences were found in the detection of visible hemorrhage/hematic residues, ulcers, erosions, varices, polyp/tumor and villous atrophy between the two groups.

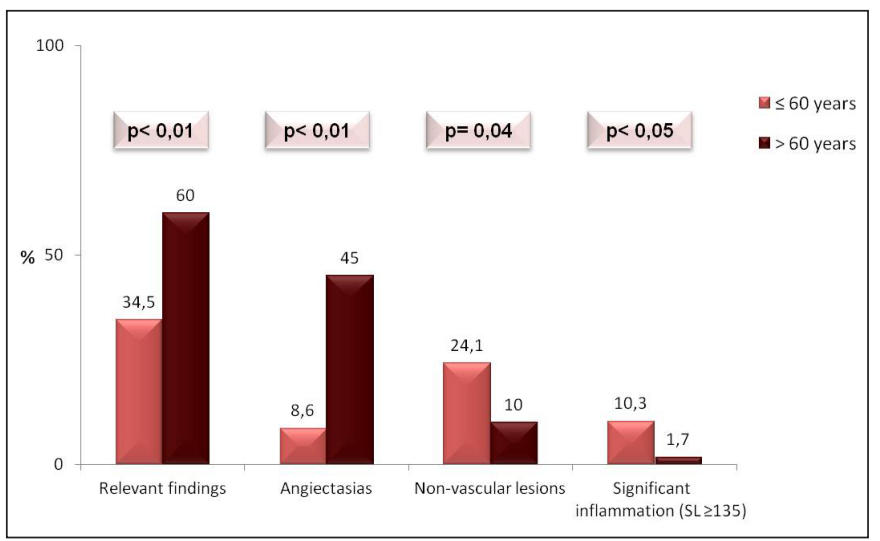

FIGURE 2. SBCE findings in IDA according to age.

\section{DISCUSSION}

SBCE is currently widely accepted and recommended as firstline investigation tool in OGIB. Our study confirms that SBCE has a significant role in the study of IDA providing valuable diagnostic information in nearly half of patients. Other investigators have reported DY ranging from $27 \%$ to $77 \% \%^{(7,21)}$ and Koulaouzidis et al. reported, in a recent systematic review, a pooled diagnostic yield of $66.6 \%{ }^{(10)}$. We were also able to confirm that SBCE has greater diagnostic performance in older patients, with $60 \%$ DY for patients over 60 years. The latter finding strengthens previous evidence that older patients have higher DY, however different authors have presented different age cut-offs and, until now, no clear age delimitation was consistently established ${ }^{(11-14)}$. The higher
DY in patients over 60 years is usually attributed to their higher comorbidity and medication burden since previous studies reported that chronic liver disease, hematologic disease, chronic renal failure and anticoagulants intake influence diagnostic yield in older patients ${ }^{(11)}$. In our cohort such co-morbidities and therapies were not significantly associated with higher diagnostic yield which may indicate that other factors influence DY. Despite higher DY in older people, younger patients have significant pathology detected by SBCE in our cohort (34\% DY) and other authors reported DY of $28 \%-50 \%$ in younger age groups ${ }^{(11,13,14)}$.

In our cohort, we found significantly higher DY in male gender. Some authors have reported that SBCE has low DY in premenopausal women with iron-deficiency anemia $(13.7 \%)^{(22)}$. Since nearly a third of the women in our sample have $\leq 45$ years, and we did not consider pre-menopausal status as an exclusion criterion for our study, this may account for the differences found between genders. What is more, the inclusion of young women irrespective of their pre-menopausal status may contribute to the lower diagnostic yield reported in younger patients.

We also found that patients with longer small bowel transit time (SBTT) have higher DY. Faster small bowel transit can eventually translate into a higher risk of missed lesions, particularly in the first tercile and several authors reported higher diagnostic yield with longer SBTT, including for SBCE performed in OGIB study ${ }^{(23)}$. PillCam ${ }^{\circledR}$ SB3 aims to overcome this limitation, by providing adaptable frame rate technology. However, in our cohort, even for PillCam ${ }^{\circledR}$ SB3, longer small bowel transit time is significantly associated with significant finding detection on SBCE.

In our cohort the most frequent finding were angiectasias in $27.1 \%$ of all patients, particularly in patients $>60$ years, who had angiectasia in $45 \%$ of cases, and in patients with hypertension and dyslipidemia. The former finding is in concordance with the literature that consistently associates higher angioectasia detection with older patients ${ }^{(11-14,24)}$. The pathogenesis of GI angioectasias is not fully understood, but some authors advocate that angioectasias should be regarded as degenerative lesions of aging, caused by chronic intermittent low-grade obstruction of veins, capillaries, and arterioles that supply the mucosa ${ }^{(25)}$. Also, previous authors have described hypercholesterolemia and hypertension as predictors of angioectasias, comorbidities increasingly more frequent with age and that may contribute to the higher prevelance of this finding in older patients ${ }^{(24)}$.

We found significant inflammation, assessed by a Lewis Score $>135$, more frequently in younger patients, with a mean age of $45 \pm 15.7$ years. For the majority of these patients Crohn's disease (CD) diagnosis was established during follow up, which is in agreement with the previously described high diagnostic accuracy and sensitivity of LS>135 for CD diagnosis ${ }^{(26)}$. This finding is also consistent with the widespread knowledge that inflammatory enteritis are more prevalent in younger populations and stresses the need to consider this diagnosis in patients presenting solely with IDA.

Even though all patients in our cohort had undergone upper and lower gastrointestinal endoscopy before SBCE, relevant findings in segments other than small bowel were reported in $20.3 \%$ of examinations, mostly in the stomach $(17.8 \%)$. Other authors have reported extra-small bowel findings in $7 \%$ to $23 \%{ }^{(27,28)}$ of SBCE performed in the study of OGIB. Despite significant extra-small bowel findings detection rates, both Gilbert et al. ${ }^{(29)}$ and Selby et al. ${ }^{(30)}$ proved that a second look endoscopy before SBCE has low diagnostic yield, is not cost-effective, and is not recommended in 
current guidelines ${ }^{(9)}$. Furthermore, in our sample, half of patients with extra-small bowel findings also had relevant small bowel findings reinforcing the need to assess this gastrointestinal segment in patients with previous unremarkable upper and lower gastrointestinal endoscopy.

Limitations of our study include its retrospective nature, making our sample widely heterogeneous in terms of therapeutical approach.

\section{CONCLUSION}

In our cohort SBCE diagnosed relevant findings in the setting of IDA in almost half the patients. The DY was higher in patients older than 60 years $(60 \%)$, with vascular lesions being more frequent in this age group. Despite the lower DY in patients $\leq 60$ years, significant pathology is also found in this age group, mainly of inflammatory type.

\section{Authors' contribution}

Xavier S performed the literature search, collected and analyzed clinical data, designed the text structure and wrote the text. Magalhães $\mathrm{J}$ and Moreira $\mathrm{MJ}$ contributed to analysis and interpretation of data and made several critical corrections and revisions. Rosa B and Cotter J suggested the theme to be reviewed, and made the several critical corrections and revisions, including English editing, until the submitted version was achieved. All authors approved the final version of the article.

Xavier S, Magalhães J, Rosa B, Moreira MJ, Cotter J. Impacto da enteroscopia por cápsula na anemia ferropénica: influência da idade do doente no rendimento diagnóstico. Arq Gastroenterol. 2018,55(3):242-6.

RESUMO - Contexto - A anemia ferropénica constitui uma das principais indicações para realização de enteroscopia por cápsula. A literatura sugere que o rendimento diagnóstico é influenciado pela idade do doente, contudo, não é consensual o grupo etário para o qual o rendimento diagnóstico é maior. Objetivo - Clarificar as diferenças de rendimento diagnóstico e incidência de achados específicos de acordo com a idade. Métodos - Estudo retrospetivo unicêntrico. Incluídos 118 doentes que realizaram sistematicamente enteroscopia por cápsula no estudo de anemia ferropénica. Todos os vídeos foram revistos e foram reportados os achados no intestino delgado que pudessem ser a causa da anemia ferropénica. Excluídas enteroscopia por cápsula incompletas. Comparados os achados entre doentes com $\leq 60$ e $>60$ anos. Resultados - Doentes com idade média de 58 anos (SD $\pm 17,9)$, $69,5 \%$ do género feminino ( $\mathrm{n}=82$ ). O rendimento diagnóstico global foi de $49 \%$ (58/118), sendo superior em doentes $>60$ anos (36/60, rendimento diagnóstico $60 \%$ ) do que em doentes $\leq 60$ anos (20/58, 34\%). As angiectasias foram mais frequentemente reportadas em doentes $>60$ anos $(45 \%$ vs $9 \%$, $P<0,01$ ). Nos doentes com $\leq 60$ anos foi mais frequentemente reportada inflamação significativa (Score de Lewis $>135$ em $10,3 \%$ vs $1,7 \%, P<0,05$ ) e lesões não vasculares $(24 \%$ vs $10 \%, P=0,04)$. Conclusão - Na nossa amostra, a enteroscopia por cápsula revelou-se importante no estudo da anemia ferropénica detectando achados relevantes em cerca de metade dos doentes. O rendimento diagnóstico foi maior em doentes com mais de 60 anos $(60 \%)$, sendo as lesões vasculares mais frequentes neste grupo. Apesar do menor rendimento diagnóstico em indivíduos até aos 60 anos, foi detectada patologia relevante neste grupo, em especial do tipo inflamatório.

DESCRITORES - Anemia. Endoscopia por cápsula. Intestino delgado.

\section{REFERENCES}

1. WHO. Global nutrition targets 2025: anaemia policy brief (WHO/NMH/ NHD/14.4). Geneva: World Health Organization; 2014.

2. Gaskell H, Derry S, Andrew Moore R, McQuay HJ. Prevalence of anaemia in older persons: systematic review. BMC Geriatrics. 2008;8:1.

3. Goddard AF, James MW, McIntyre AS, Scott BB, British Society of G. Guidelines for the management of iron deficiency anaemia. Gut. 2011;60:1309-16.

4. Ladas SD, Triantafyllou K, Spada C, et al. European Society of Gastrointestinal Endoscopy (ESGE): recommendations (2009) on clinical use of video capsule endoscopy to investigate small-bowel, esophageal and colonic diseases. Endoscopy. 2010;42:220-7.

5. Liao Z, Gao R, Xu C, Li ZS. Indications and detection, completion, and retention rates of small-bowel capsule endoscopy: a systematic review. Gastrointestinal endoscopy. 2010;71:280-6.

6. Triester SL, Leighton JA, Leontiadis GI, Fleischer DE, Hara AK, Heigh RI, et al. A meta-analysis of the yield of capsule endoscopy compared to other diagnostic modalities in patients with obscure gastrointestinal bleeding. Am J Gastroenterol. 2005; 100:2407-18.

7. Milano A, Balatsinou C, Filippone A, Caldarella MP, Laterza F, Lapenna D, et al. A prospective evaluation of iron deficiency anemia in the GI endoscopy setting: role of standard endoscopy, videocapsule endoscopy, and CT-enteroclysis. Gastrointest Endosc. 2011;73:1002-8.

8. Pasha SF, Leighton JA, Das A, Harrison ME, Decker GA, Fleischer DE, Sharma VK. Double-balloon enteroscopy and capsule endoscopy have comparable diagnostic yield in small-bowel disease: a meta-analysis. Clin Gastroenterol Hepatol. 2008;6:671-6.

9. Pennazio M, Spada C, Eliakim R, Keuchel M, May A, Mulder CJ, et al. Small-bowel capsule endoscopy and device-assisted enteroscopy for diagnosis and treatment of small-bowel disorders: European Society of Gastrointestinal Endoscopy (ESGE) Clinical Guideline. Endoscopy. 2015;47:352-76.
10. Koulaouzidis A, Rondonotti E, Giannakou A, Plevris JN. Diagnostic yield of small-bowel capsule endoscopy in patients with iron-deficiency anemia: a systematic review. Gastrointestinal endoscopy. 2012;76:983-92.

11. Sidhu PS, McAlindon ME, Drew K, Sidhu R. The Utility of Capsule Endoscopy in Patients under 50 Years of Age with Recurrent Iron Deficiency Anaemia: Is the Juice Worth the Squeeze? Gastroenterol Res Pract. 2015;2015:948574.

12. Koulaouzidis A, Yung DE, Lam JH, Smirnidis A, Douglas S, Plevris JN. The use of small-bowel capsule endoscopy in iron-deficiency anemia alone; be aware of the young anemic patient. Scand J Gastroenterol. 2012;47:1094-100.

13. Muhammad A, Pitchumoni CS. Evaluation of Iron deficiency anemia in older adults the role of wireless capsule endoscopy. J Clin Gastroenterol. 2009;43:627-31.

14. Scaglione G, Russo F, Franco MR, Sarracco P, Pietrini L, Sorrentini I. Age and video capsule endoscopy in obscure gastrointestinal bleeding: a prospective study on hospitalized patients. Dig Dis Sci. 2011;56:1188-93.

15. Gralnek IM, Seidman E, Seidman E, Leighton JA, Legnani P, Lewis BS. Development of a capsule endoscopy scoring index for small bowel mucosal inflammatory change. Aliment Pharmacol Ther. 2008;27:146-54.

16. Cotter J, de Castro FD, Magalhaes J, Moreira MJ, Rosa B. Finding the solution for incomplete small bowel capsule endoscopy. World J Gastrointest Endosc. 2013;5:595-9.

17. Rosa BJ, Barbosa M, Magalhaes J, Rebelo A, Moreira MJ, Cotter J. Oral purgative and simethicone before small bowel capsule endoscopy. World J Gastrointest Endosc. 2013;5:67-73.

18. Cotter J, Magalhaes J, de Castro FD, Barbosa M, Carvalho PB, Leite S, et al. Virtual chromoendoscopy in small bowel capsule endoscopy: New light or a cast of shadow? World J Gastrointest Endosc. 2014;6:359-65.

19. Dias de Castro F, Magalhaes J, Boal Carvalho P, Cúrdia Gonçalves T, Rosa B, Moreira MJ, Cotter J. Improving diagnostic yield in obscure gastrointestinal bleeding--how virtual chromoendoscopy may be the answer. Eur J Gastroenterol Hepatol. 2015;27:735-40. 
20. Mergener K, Ponchon T, Gralnek I, Pennazio M, Gay G, Selby W, et al. Literature review and recommendations for clinical application of small-bowel capsule endoscopy, based on a panel discussion by international experts. Endoscopy. 2007;39:895-909.

21. Papadopoulos AA, Triantafyllou K, Kalantzis C, Adamopoulos A, Ladas D, Kalli $\mathrm{T}$, et al. Effects of ageing on small bowel video-capsule endoscopy examination. Am J Gastroenterol. 2008;103:2474-80.

22. Garrido Duran C, Iyo Miyashiro E, Paez Cumpa C, Khorrami Minaei S, Erimeiku Barahona A, Llompart Rigo A. [Diagnostic yield of video capsule endoscopy in premenopausal women with iron-deficiency anemia]. [Article in Spanish] Gastroenterol Hepatol. 2015;38:373-8.

23. Westerhof J, Koornstra JJ, Hoedemaker RA, Sluiter WJ, Kleibeuker JH, Weersma RK. Diagnostic yield of small bowel capsule endoscopy depends on the small bowel transit time. World J Gastroenterol. 2012;18:1502-7.

24. Curdia Goncalves T, Magalhaes J, Boal Carvalho P, Moreira MJ, Rosa B, Cotter J. Is it possible to predict the presence of intestinal angioectasias? Diagnostic and therapeutic endoscopy 2014;2014:461602.

25. Yamada T, Alpers DH, Kalloo AN, Kaplowitz N, Owyang C, Powell DW. (2009). Textbook of Gastroenterology, Fifth Edition. Blackwell Publishing Ltd. Doi: $10.1002 / 9781444303254$
26. Monteiro S, Boal Carvalho P, Dias de Castro F, Magalhães J, Machado F, Moreira MJ, et al. Capsule endoscopy: diagnostic accuracy of lewis score in patients with suspected Crohn's disease. Inflamm Bowel Dis. 2015;21:2241-6.

27. van Turenhout ST, Jacobs MA, van Weyenberg SJ, Herdes E, Stam F, Mulder CJ, Bouma G. Diagnostic yield of capsule endoscopy in a tertiary hospital in patients with obscure gastrointestinal bleeding. J Gastrointestin Liver Dis. 2010;19:141-5

28. del Risco FG, Lopez EA. Diagnostic Performance of, and findings from, Capsule Endoscopy for patients with Gastrointestinal Bleeding with Obscure Origins at the Clínica Universitaria San Juan de Dios in Cartagena, Colombia. Rev Col Gastroenterol. 2014;29:101-10.

29. Gilbert D, O'Malley S, Selby W. Are repeat upper gastrointestinal endoscopy and colonoscopy necessary within six months of capsule endoscopy in patients with obscure gastrointestinal bleeding? J Gastroenterol Hepatol. 2008;23:1806-9.

30. Selby W. Can clinical features predict the likelihood of finding abnormalities when using capsule endoscopy in patients with GI bleeding of obscure origin? Gastrointest Endosc. 2004;59:782-7. 